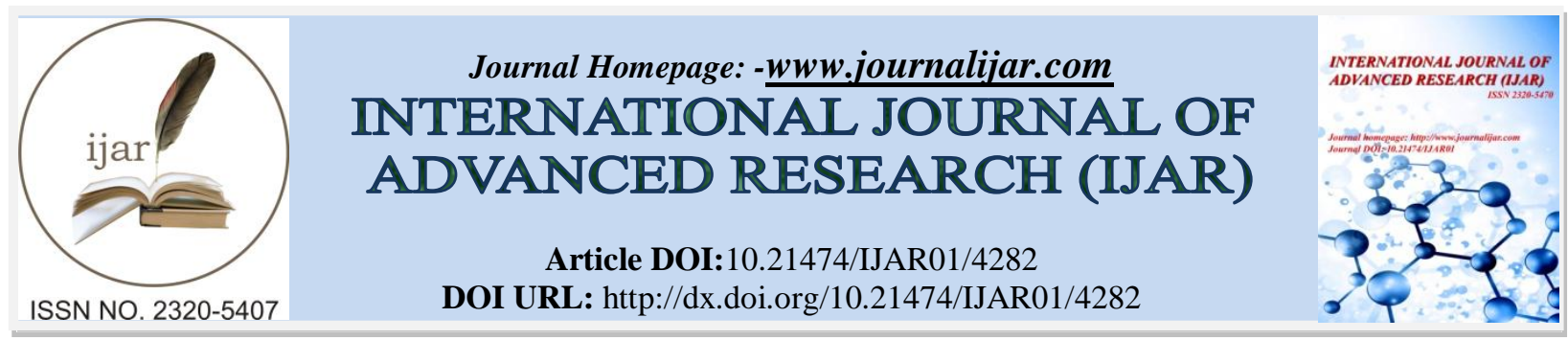

RESEARCH ARTICLE

\title{
COMPARATIVE STUDY OF ASTIGMATISM BETWEEN CONVENTIONAL ECCE AND MANUAL SMALL INCISION CATARACT SURGERY- A PROSPECTIVE STUDY.
}

Dr. ShivajiL. Padamukhi, " Dr. Shivayogi R Kusagur and Dr. Vasantha Kumar S H.

Professor and Oculoplasty Surgeon, Department Of Ophthalmology, J. J .M. Medical College, Davangere Karnataka State, India.

\section{Manuscript Info}

Manuscript History

Received: 28 March 2017

Final Accepted: 30 April 2017

Published: May 2017

Key words:-

MSICS (Manual Small Incision

Cataract Surgery), conventional ECCE

(Extra-Capsular Cataract Extraction),

Astigmatism

\section{Abstract}

Objective: To study and compare the incidence, amount, type and course of astigmatism in conventional ECCE and manual small incision cataract surgery.

Materials and Methods: This is a prospective study of 100 consecutive patients, assigned to undergo conventional ECCE (50 cases) and manual small incision cataract surgery (50 cases).

Results: The surgery induced astigmatism (SIA) was With The Rule(WTR) in conventional ECCE group at first week the mean surgery induced astigmatism was $3.02 \mathrm{D}, 1.82 \mathrm{D}$ at sixth week and $1.12 \mathrm{D}$ at third month. The induced astigmatism in MSICS was Against The Rule (ATR), at first week the mean SIA was 1.41D,1.61D at sixth week and 1.71D at third month.

Conclusions: Manual small incision cataract surgery induces minimal amount of ATR astigmatism in early post-operative period compared to conventional ECCE, which induces moderate amount of WTR astigmatism. Post-operative astigmatic shift was observed till the end of 3rd month in conventional ECCE. Whereas MSICS group, the astigmatism was stabilized at 6th week in majority of the cases.

Copy Right, IJAR, 2017,. All rights reserved.

\section{Introduction:-}

Cataract surgery is the most common ophthalmic surgery done all over the world. 10 million cataracts are being operated every year worldwide. But there is a need to do at least 30 million per year for the indefinite future. Cataract surgery rate should increase to attain this goal ${ }^{1}$.

Phacoemulsification is considered the gold standard of care for cataract surgery. Cost in terms of equipment, training and high proportion of eyes with dense nuclei and mature cataract has limited its use in the developing countries ${ }^{2}$.

Conventional ECCE is the most frequently done cataract procedure till now in developing world including India. But disadvantages of conventional ECCE like large section, delayed visual rehabilitation, large surgery induced astigmatism and suture related complication made surgeons to think of alternative procedures. Manual small incision cataract surgery where in nucleus is removed through small (5-7mm) posteriorly placed scleral incision has some of the advantages of phacoemulsification like early visual 
rehabilitation, less induced astigmatism and no suture related complication has emerged as an alternative to phacoemulsification.

Present study is being done to compare astigmatism produced by conventional ECCE and manual small incision cataract surgery.

\section{Aims AndObjectives:-}

1. To study and compare the incidence, amount, type and course of astigmatism in conventional ECCE and manual small incision cataract surgery.

2. To study relationship between preoperative astigmatism to postoperative astigmatism.

\section{Materials and Methods:-}

This is a prospective study of 100 consecutive patients, assigned to undergo conventional ECCE (50 cases) and manual small incision cataract surgery (50 cases). Study was done from September 2002 to April 2004 at Bapuji Hospital and Chigateri General Hospital, Davangere, Karnataka

The surgeries were done by different consultants and residents in the Department of Ophthalmology, J.J.M. Medical College, Davangere.

\section{Pre-operative Assessment:-}

Patients were admitted one day before the surgery. Detailed history was taken of each patient and thorough anterior segment examination was performed using slit lamp. Visual acuity was checked with Snellen's visual acuity chart and pinhole improvement was noted. After pupillary dilatation detailed fundus examination and retinoscopy was done, lenticular opacity was assessed and graded. IOP was measured with Schiotz tonometer and patency of lacrinal system were checked. Keratometry was carried out using the Bausch and Lomb keratometer. Axial length was measured by a Sonomed A-scan unit and IOL power was calculated using SRKII formula. Routine investigations were done to rule out diabetes, hypertension, and HIV, HBsAg infections.

Cataract patients above 40 years were included in this study. Paediatric cataract, traumatic, complicated cataract, cataract associated with glaucoma, cases with pterygium/corneal opacity/corneal degeneration and dystrophies, complications occurring during and after surgery were excluded from this study.

\section{Surgical Technique:-}

All cases were done under local peribulbar anaesthesia. Conventional ECCE or Manual Small Incision Cataract Surgery Techniques were performed.

A detailed post-operative examination of patients was done on $1^{\text {st }}$ day, $1^{\text {st }}$ week, $6^{\text {th }}$ week and 3 months. The examination included checking visual acuity, keratometry and slit lamp biomicroscopy. At the end of six weeks a final best corrected subjective refraction was performed and the spectacles prescribed. All the changes of keratometry readings were recorded tabulated for each corresponding period. Cases with axes 70 - $110^{\circ}$ were considered as WTR astigmatism and $160-20^{\circ}$ axes were considered as ATR. In between the axes were considered as oblique astigmatism and those cases were excluded from the study. SIA was calculated using algebraic method.

\section{Observations and Results:-}

100 cases were studied, in which 50 cases underwent conventional ECCE and 50 cases MSICS. 49 cases were female and 51 cases were male.

The majority who underwent cataract surgery were in the age group of $56-60$. The mean age group of patients in the conventional ECCE $56.8( \pm 5.9)$ years was similar $(p>0.5)$ to the mean age of $57( \pm 7.5)$ years in MSICS group.

In MSICS group, superior tunnel was constructed in 37 patients, in which straight incision was put in 25 patients and frown incision in 12 patients. In 13 patients temporal tunnel was constructed. 
No statistically significant difference in pre-operative visual acuity was found between two group ( $p=$ $0.25, N S$ ). Majority of the patients who underwent cataract surgery in both the groups had vision $<1 / 60$, the next group was $6 / 24$ to $6 / 60$.

Majority of cases in conventional ECCE (68\%) had ATR astigmatism. In comparison ( $p<0.01$ S) to MSICS group where WTR and ATR cases were almost equal. Mean astigmatism in conventional ECCE group was $0.75 \mathrm{D}$ ATR and in MSICS group was $0.04 \mathrm{D}$ ATR.

Post-operatively, in conventional ECCE at $3^{\text {rd }}$ month, cases with WTR astigmatism (9 cases), the astigmatism increased in 6 patients and decreased in 3 patients. Cases with ATR astigmatism (34 cases), the astigmatism decreased in 28 patients and increased in 5 patients and remained same in 1 patient. Cases with no astigmatism (7 cases), 6 cases shifted to WTR and 1 case to ATR.

In MSICS group at $3^{\text {rd }}$ month, cases with WTR astigmatism (20 cases), the astigmatism decreased in 19 patients and increased in 1 patient. Cases with ATR astigmatism, the astigmatism decreased in 13 patients and increased in 12 patients, cases with no astigmatism (4 cases), all shifted to ATR at the end of $3^{\text {rd }}$ month.

،

It was observed that in conventional ECCE, WTR astigmatism increased, ATR astigmatism decreased and cases with no astigmatism converted to WTR in majority of patients. In MSICS group, WTR astigmatism decreased, ATR astigmatism increased and no astigmatism converted to ATR astigmatism in superior MSICS group. Whereas ATR astigmatism decreased and WTR astigmatism increased in temporal MSICS group.

Post-operatively, majority of the patients had WTR astigmatism, 40 patients $(80 \%)$ at $6^{\text {th }}$ week, 30 patients $(60 \%)$ at $3^{\text {rd }}$ month in conventional ECCE and ATR astigmatism in 38 patients $(76 \%)$ and 41 patients $(82 \%)$ at $3^{\text {rd }}$ month in MSICS group.

3 patients in conventional ECCE and 6 patients in MSICS group missed $1^{\text {st }}$ day follow up.

Table1:- SIA in conventional ECCE and MSICS.

\begin{tabular}{|l|c|c|c|}
\hline & SIA first week & SIA sixth week & SIA third month \\
\hline conventional ECCE & $3.02 \mathrm{D}$ & $1.82 \mathrm{D}$ & $1.12 \mathrm{D}$ \\
\hline MSICS & $1.41 \mathrm{D}$ & $1.61 \mathrm{D}$ & $1.71 \mathrm{D}$ \\
\hline
\end{tabular}

The surgery induced astigmatism (SIA) was With The Rule (WTR) in conventional ECCE group at first week the mean surgery induced astigmatism was $3.02 \mathrm{D}, 1.82 \mathrm{D}$ at sixth week and $1.12 \mathrm{D}$ at third month. The induced astigmatism in MSICS was Against The Rule (ATR), at first week the mean SIA was 1.41D,1.61D at sixth week and 1.71D at third month. Patients have better unaided vision in ATR astigmatism postoperatively as quoted in the series by Dr. Kamal Nagpal ${ }^{3}$.

There were significantly more patients with un aided vision of $6 / 18$ or better in MSICS group than in conventional ECCE group. $34 \%$ at $1^{\text {st }}$ day, $78 \%$ at $1^{\text {st }}$ week and $80 \%$ at $6^{\text {th }}$ week in MSICS group compared to only $4.2 \%$ at $1^{\text {st }}$ day, $16 \%$ at $1^{\text {st }}$ week and $60 \%$ at $6^{\text {th }}$ week attained vision of $6 / 18$ or better. But no statistical difference $(p=0.2, N S)$ was observed between study groups at $3^{\text {rd }}$ month. $2.1 \%$ of patients at $1^{\text {st }}$ day, $14 \%$ at $1^{\text {st }}$ week, $6 \%$ at $6^{\text {th }}$ week and $3^{\text {rd }}$ month gained unaided vision of $6 / 9$ or better at any follow up period.

\section{Discussion:-}

Cataract is the main cause of avoidable blindness worldwide, with the developing world accounting for three quarters of blindness. Despite the 10 to 12 million cataract operations performed globally, cataract blindness is still thought to be increasing by 1-2 million per year. In order to effectively address this increasing backlog, significant efforts are being undertaken to increase the out put of cataract surgical services in many developing countries and to make cataract surgery affordable to all people irrespective of 
their economic status.

Results of this study are consistent with previous reports that MSICS induces a small amount of ATR astigmatism and gives early visual rehabilitation to the patients than those who have conventional ECCE which induces moderate amount of WTR astigmatism.

Bidaye Shashank and Vilas Bidaye ${ }^{4}$ (1999) compared $5.5 \mathrm{~mm}$ suture less scleral tunnel incision with 8 $\mathrm{mm}$ conventional ECCE. They studied 100 consecutive patients. Pre-operative mean astigmatism was 0.75D WTR in SICS, 0.84D WTR in conventional ECCE group. The mean induced astigmatism in SICS was 1.05D ATR at $1^{\text {st }}$ month, 0.75D ATR at $3^{\text {rd }}$ month and in conventional ECCE group, 2.24D WTR at $1^{\text {st }}$ month and $1.85 \mathrm{D}$ WTR at $3^{\text {rd }}$ month.

Kshetrapal Arun and Ramesh Kshetrapal ${ }^{5}$ (1999) studied $5.5 \mathrm{~mm}$ SICS. 78\% had astigmatism < 1.5D and only $22 \%$ had astigmatism $>1.5 \mathrm{D}$. $81.8 \%$ obtained visual acuity between $6 / 6$ to $6 / 12$ at $4^{\text {th }}$ week postoperatively.

Pandey D.J. et $\mathrm{al}^{6}$. (2000) compared conventional ECCE with manual SICS. Post-operative induced astigmatism was $<1 \mathrm{D}$ in majority of cases. In comparison astigmatism was around $1.5 \mathrm{D}$ in conventional ECCE cases.

Dabral Tulika et al ${ }^{7}$. (2000) studied 600 cases of sutureless SICS. $71 \%$ of cases had astigmatism < 1.5D and $89 \%$ had BCVA of $6 / 12$ or better at $40^{\text {Ih }}$ postoperative week.

\section{Conclusion:-}

- Manual small incision cataract surgery induces minimal amount of ATR astigmatism in early postoperative period compared to conventional ECCE, which induces moderate amount of WTR astigmatism.

- MSICS give better uncorrected visual acuity in early post-operative period compared to conventional ECCE.

- Post-operative astigmatic shift was observed till the end of 3rd month in conventional ECCE. Whereas MSICS group, the astigmatism was stabilized at 6th week in majority of the cases.

- MSICS had definitive advantages over conventional ECCE in terms of early visual rehabilitation, minimal surgery induced astigmatism and no suture related complications.

\section{Bibliography:-}

1. Foster A, "Cataract and vision 2020 - the right to sight" Initiative $\mathrm{Br} \mathrm{J}$ Ophthalmol. 2001; 85: 635637.

2. Hennig A, Kumar J, Yorston $\mathrm{P}$, et al., "Sutureless cataract surgery with nucleus extraction: outcome of a prospective study in Nepal". Br J Ophthalmol, 2003; 87: 266-270.

3. Nagpal K, Trived R, Desai C, Vasavada AR. "Desirable post-operative refraction in pseudophakes". In Lavingia BC Editor, Proceedings of $57^{\text {th }}$ All India Ophthalmological Society Conference, Cochin: Nom Enterprises. 1999;161-162.

4. Bidaye Shashank, Vilas Bidaye. "Comparative study of intraocular lens implantation through $5.5 \mathrm{~mm}$ sutureless scleral tunnel incision with, a conventional $8.0 \mathrm{~mm}$ or larger incision". In Lavingia BC Editor, Proceedings of $57^{\text {th }}$ All India Ophthalmological Society Conference, Cochin: Nom Enterprises. 1999; 140-141.

5. Kshetrapal Arun, Kshetrapal R. "Phacoless, sutureless cataract extraction with IOL A new technique. In Lavingia BC Editor, Proceedings of 57th All India Ophthalmological Society Conference, Cochin: Nom Enterprises. 1999; 140-141.

6. Pandey DJ, Awasthi NA, Agnihotri N. et.al., "Evalution of astigmatism in small incision non-phaco technique with standard ECCE" . In Lavingia BC Editor, Procedings of $57^{\text {th }}$ All India Ophthalmological Society Conference, Cochin: Nom Enterprises, 2000: 99-101.

7. Dabral T, Natchair G, Mohan P. et al., "Manual Small incision cataract surgery (SICS) in high quality, high volume setup - A great alternative to instrumental phaco". In Lavingia BC Editor, Procedings of $57^{\text {th }}$ All India Ophthalmological Society Conference, Cochin: Nom Enterprises, 2000; 9698. 